\title{
Geometrical Optimization of Integral Balance for Normal and Side Force using GRA Method
}

\author{
Abhinandan P Ugare \\ Department of Mechanical Engineering \\ RVCE, Bengaluru \\ India, 560059
}

\begin{abstract}
In aerodynamic field more than $70 \%$ of the tests in wind tunnel require some kind of measurement with better understanding of aerodynamic specifications more efficient aircrafts possible. The force transducer used for measuring forces and moments must be rigid enough to prevent divergence as stability issue and grounding during load path transfer. A six component force transducer used for measuring three forces- lift, drag, side and three moments- pitching, yawning, rolling which placed inside a scaled model. An effort was made to increase the rigidity and sensitivity of existing cross beam flexure sensing element which measures normal force and side force with newly proposed three rectangular beams. The geometrical optimization of newly proposed flexure was carried out through Taguchi based Grey relational analysis. The results showed that increase in Sensitivity outputs compared to cross beam flexure.
\end{abstract}

\section{INTRODUCTION}

Force and moment measurement is very essential to characterize the performance of flying vehicle for design improvements. The three forces Lift, Drag, Side and three moments Pitching, Yawning, Rolling moments are the parameters to be studied. To get optimized design it is extremely important to know all these parameters at initial design phase. The forces measured in model axes later converted into wind axes. The model sting attachment is as shown in Fig.1

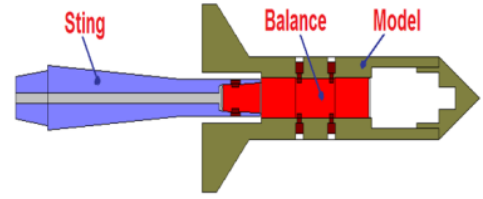

Fig. 1 Balance sting arrangement

In wind tunnels to study the performance of the scaled models, such as Launch vehicles, satellite, missiles and aircrafts a transducer is used for measuring forces and moments. The transducer generally known as balance used for measure three forces and three moments, which later converted into Lift, Drag, Side forces and Pitching, Yawning and Rolling moments Load path starts from model to balance and balance to support system known as sting. For this system to be stable it should avoid divergence for erroneous experimental results. If there is direct contact between scaled model and support system, then load directly transfers to support directly from model which results in error reading. Hence it highly demands trade-off between Sensitivity and Rigidity for designing balance structure. The most common setup for internal balance -model is shown in Fig. 2

\author{
Mr. Sujan Chakraborty \\ Assistant Professor \\ Department of Mechanical Engineering \\ RVCE, Bengaluru \\ India,560059
}

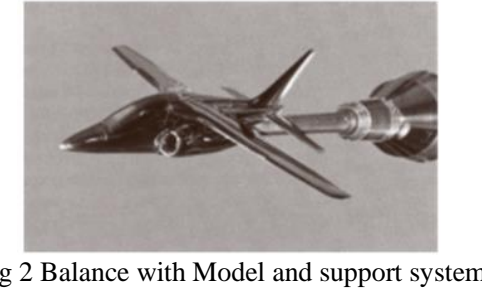

A complete design methodology of six component balance explained. Formulae derived for nominal strain at gage location and compared with Finite element models. To study the Balance performance linearity, stiffness, strain distribution and interactions were investigated [1]. An experimental study was carried out determine accuracy of rolling moment element. Rolling moment element was made of Five bar cage element and compared with a sensitive one component transducer. Both of the experimental data's were compared for the investigation [2]. Shape optimization of drag force element carried out. Rectangular parallelepiped converted into concave shape flexure and computational results showed that there is a considerable increase in the outputs for concave shaped flexure with marginal increase in the interactions [3]. Shape optimization of $25 \mathrm{~mm}$ internal balance was carried out. The material used for the balance is $17-4 \mathrm{PH}$ stainless steel. Model is prepared in Unigraphics design software and the model imported in Hypermesh software for the meshing and analysis purpose [4]. Geometrical optimization of strain gauge force transducer was carried out. Multi objective optimization for maximizing stress capacity and reduce volume. Combined Taguchi based GRA was used to optimize responses obtained from Finite element analysis [5]. The balance designed by earlier researchers [1-4] there is no mention of using three rectangular beam for measuring normal force and side force simultaneously. In this regard an existing cross beam flexure was replaced with three rectangular flexure and optimization carried for improved rigidity and sensitivity through Taguchi based Grey relational analysis.

\section{DESIGN REQUIREMENTS AND CONSIDERATIONS}

\section{A. Requirements}

The proper structural design of a balance requires accurate knowledge of the design criteria and adherence to these criteria. No explanation is presented concerning the extent to which each of these criteria exerts its influence, because their relative importance depends on the type of balance and the specific objective for which it will be used. In addition, these 
criteria are not independent, and many interactions exist between them. The requirements and considerations for the design of the balance are listed below:

- The size of the model is a limitation for the diameter

of balance which cannot exceed $32.5 \mathrm{~mm}$.

- It is designed for the loads of:

Normal Force (N1): $1334.4 \mathrm{~N}$

Side force(S1): $889.6 \mathrm{~N}$

- The instrument should be as stiff as possible and hence the deflection of the balance with respect to its longitudinal axis should be minimized because it brings in nonlinearity.

\section{B. Wheatstone bridge output}

Output for the Wheatstone is given by following equation 1 ,

$\frac{V}{V e}=k(\varepsilon 1-\varepsilon 2+\varepsilon 3-\varepsilon 4) * \frac{1}{4}(\mathrm{mV} / \mathrm{V})$

Where $\mathrm{k}$ is gage factor.

\section{STRUCTURAL DESIGN OF TRANSDUCER AND METHODOLOGY}

The balance has various sections as shown in Fig 3 an Fig 4 such as mounting end, grounding end, Side force and Lift force.

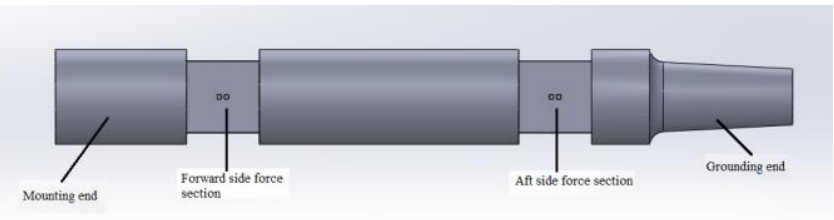

Fig 3 Side force section

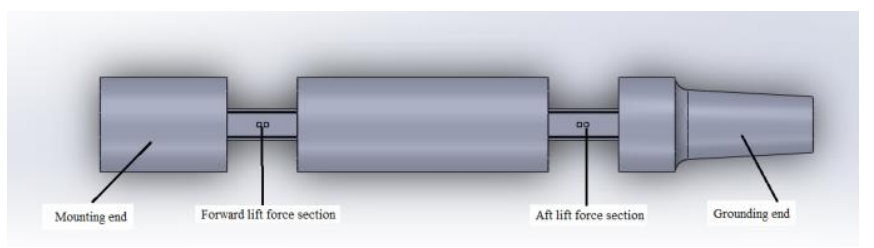

Fig 4 Lift force section

The goal is to fabricate a balance in which the selected section was sensitive in the direction of the considered component and insensitive in the other directions. This objective can be accomplished through the proper design of the sections and appropriate wiring techniques. Four active strain gauges were used to measure each component of the balance in the Wheatstone bridge circuit.

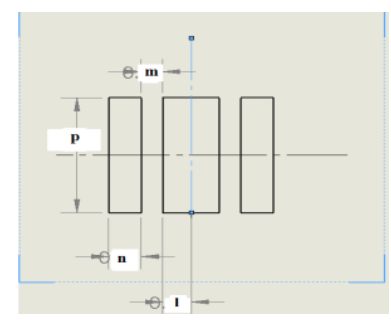

Fig.5 Sectional view of three beam flexure

The sectional view of yawing section and pitching section is shown in Fig 5 and the equations for bending stress is derived using the bending moment equations. Therefore bending stress at gauge location for normal force measuring element is given by equation 2 .

$\sigma=\mathrm{N} 1 * \mathrm{~L} * \mathrm{y} / 2 *\left(1 \mathrm{p}^{3} / 12+\mathrm{np}^{3} / 12\right)$

The bending stress at gauge location for side force is given by equation 3 .

$\sigma=\mathrm{S} 1 * \mathrm{~L} * \mathrm{y} / 2 *\left(\mathrm{pl}^{3} / 12+\mathrm{pn}^{3} / 12+\mathrm{pn}^{*}\left((1+\mathrm{m}+\mathrm{n} / 2)^{2}\right)\right.$

Where $\mathrm{p}, 1, \mathrm{~m}$ and $\mathrm{n}$ are the sectional dimensions of the Lift force and Side force measuring element as shown in Fig 5.The Fig 6 describes the methodology followed for completing this work and various tools which were employed at various stages of project. After formulating Strain equations at gage location the geometrical parameters were identified and L9 orthogonal array is set using Taguchi method for different parameter levels. Based on L9 OA CAD models of the balances were prepared in Solidworks software. These models were imported to Hyperworks software to mesh and carryout linear static analysis for given loadings. The four responses obtained from Finite element analysis were combined to form a single response with Grey relational Analysis and the optimal parameters were analysed using Minitab software.

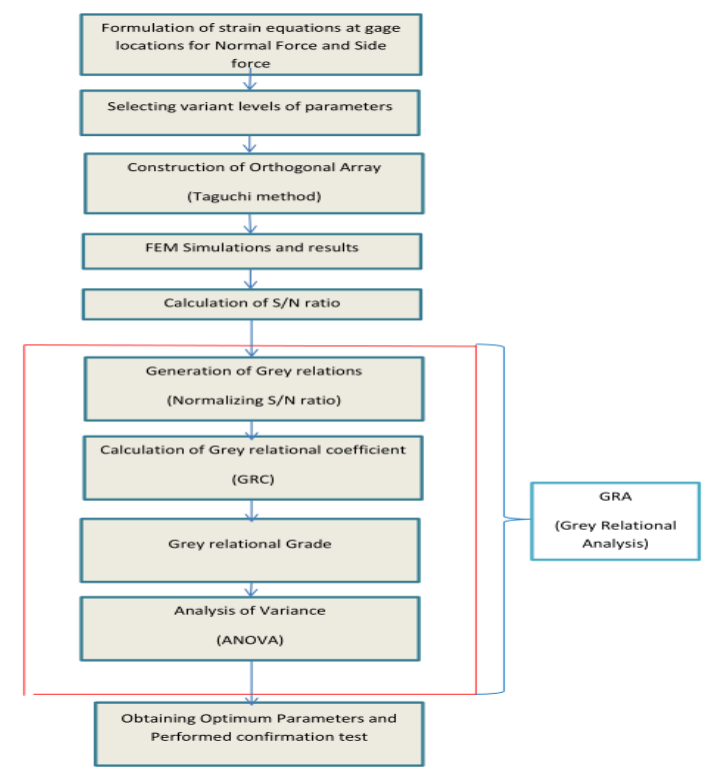

Fig. 6 Project methodology flowchart

\section{DESIGN OF EXPERIMENT AND ANALYSIS}

\section{A. Taguchi design}

The four controllable geometrical parameters under considerations are $1, \mathrm{~m}, \mathrm{n}, \mathrm{p}$.The chosen levels for each parameters is 3.Hence available orthogonal array for chosen design is L9. The minimum value of ' 1 ' should be equal to $4 \mathrm{~mm}$ for strain gage mounting and minimum value of ' $\mathrm{m}$ ' should be $0.5 \mathrm{~mm}$ for Electric Discharge machining. The Taguchi design for four parameters for three different levels is considered as shown in Table 1 and Table 2 shows number of runs as per L9 orthogonal array formulated in Minitab software version 19. Table 3 and Table 4 contains analyzed data and $\mathrm{S} / \mathrm{N}$ ratio for deformation and strain at gage locations respectively. 
Table 1 Parameters levels

\begin{tabular}{|c|c|c|c|c|c|}
\hline Sr. No & Parameter & unit & Level 1 & Level 2 & Level 3 \\
\hline 1 & $\mathrm{P}$ & $\mathrm{mm}$ & 24.53 & 25.53 & 26.53 \\
\hline 2 & 1 & $\mathrm{~mm}$ & 4 & 4.5 & 5 \\
\hline 3 & $\mathrm{~m}$ & $\mathrm{~mm}$ & 0.5 & 1 & 1.5 \\
\hline 4 & $\mathrm{n}$ & $\mathrm{mm}$ & 0.88 & 1.88 & 2.88 \\
\hline
\end{tabular}

Table 2 Experimental values for different variables

\begin{tabular}{|l|l|l|l|l|} 
& $\mathbf{p}$ & $\mathbf{l}$ & $\boldsymbol{m}$ & $\mathbf{n}$ \\
\hline $\mathbf{1}$ & 24.53 & 4.0 & 0.5 & 0.88 \\
\hline $\mathbf{3}$ & 24.53 & 4.5 & 1.0 & 1.88 \\
\hline $\mathbf{4}$ & 24.53 & 5.0 & 1.5 & 2.88 \\
\hline $\mathbf{5}$ & 25.53 & 4.0 & 1.0 & 2.88 \\
\hline $\mathbf{6}$ & 25.53 & 4.5 & 1.5 & 0.88 \\
\hline $\mathbf{7}$ & 25.53 & 5.0 & 0.5 & 1.88 \\
\hline $\mathbf{8}$ & 26.53 & 4.0 & 1.5 & 1.88 \\
\hline $\mathbf{9}$ & 26.53 & 4.5 & 0.5 & 2.88 \\
\hline
\end{tabular}

Table 3 Analyzed data $\mathrm{S} / \mathrm{N}$ ratio for deformations

\begin{tabular}{|c|cc|cc|}
\hline \multirow{2}{*}{$\begin{array}{c}\text { Orthogonal } \\
\text { Array }\end{array}$} & \multicolumn{2}{|c|}{ Deformations(mm) } & \multicolumn{2}{c|}{ S/N ratio } \\
\cline { 2 - 5 } & N1 load & S1 load & N1 load & S1 load \\
\hline 1 & 0.568 & 1.361 & 4.91303 & -2.6772 \\
2 & 0.468 & 0.641 & 6.59508 & 3.86284 \\
3 & 0.413 & 0.388 & 7.681 & 8.22337 \\
4 & 0.421 & 0.523 & 7.51436 & 5.62997 \\
5 & 0.483 & 0.884 & 6.32106 & 1.07096 \\
6 & 0.424 & 0.59 & 7.45268 & 4.58296 \\
7 & 0.425 & 0.639 & 7.43222 & 3.88998 \\
8 & 0.384 & 0.49 & 8.31338 & 6.19608 \\
9 & 0.442 & 0.775 & 7.09156 & 2.21397 \\
\hline
\end{tabular}

Table 4 Analyzed data $\mathrm{S} / \mathrm{N}$ ratio for strains

\begin{tabular}{|c|cc|cc|}
\hline \multirow{2}{*}{$\begin{array}{c}\text { Orthogonal } \\
\text { Array }\end{array}$} & \multicolumn{2}{|c|}{ Microstains } & \multicolumn{2}{c|}{ S/N ratio } \\
\cline { 2 - 5 } & N1 load & S1 load & N1 load & S1 load \\
\hline 1 & 808.419 & 1329.05 & 58.1527 & 62.4709 \\
2 & 623.779 & 802.215 & 55.9006 & 58.0858 \\
3 & 485.887 & 473.161 & 53.7307 & 53.5002 \\
4 & 514.538 & 605.607 & 54.2283 & 55.6438 \\
5 & 662.548 & 1096.61 & 56.4244 & 60.801 \\
6 & 516.177 & 698.468 & 54.256 & 56.8829 \\
7 & 571.354 & 810.409 & 55.1381 & 58.1741 \\
8 & 455.43 & 555.505 & 53.1684 & 54.8938 \\
9 & 573.354 & 912.414 & 55.1685 & 59.2038 \\
\hline
\end{tabular}

\section{B. Finite element model}

The CAD models from Solidworks software were converted into STEP files for Linear Static Analysis to carry out Linear Static Analysis in Hyperworks software. The CAD models were imported in Hypermesh software. Balance was meshed using CTETRA elements with the size of $2 \mathrm{~mm}$ for initial runs to reduce the analysis time. After optimization convergence studies carried out and element size was taken as 0.5.The results compared with analytical data and difference was $5 \%$.Constraints applied in all DOF at taper region of balance. Loads acted on nodes created at loading station and these nodes are interconnected to face of balance model mounting end using rigid elements (RBE2), similar to calibration loading arrangement for load transfer. Optistruct solver used for linear static analysis. Hyperview was used to capture the data of Stress at gage location and maximum deformation due to different loading cases. The steps in FEM shown in Fig. 7
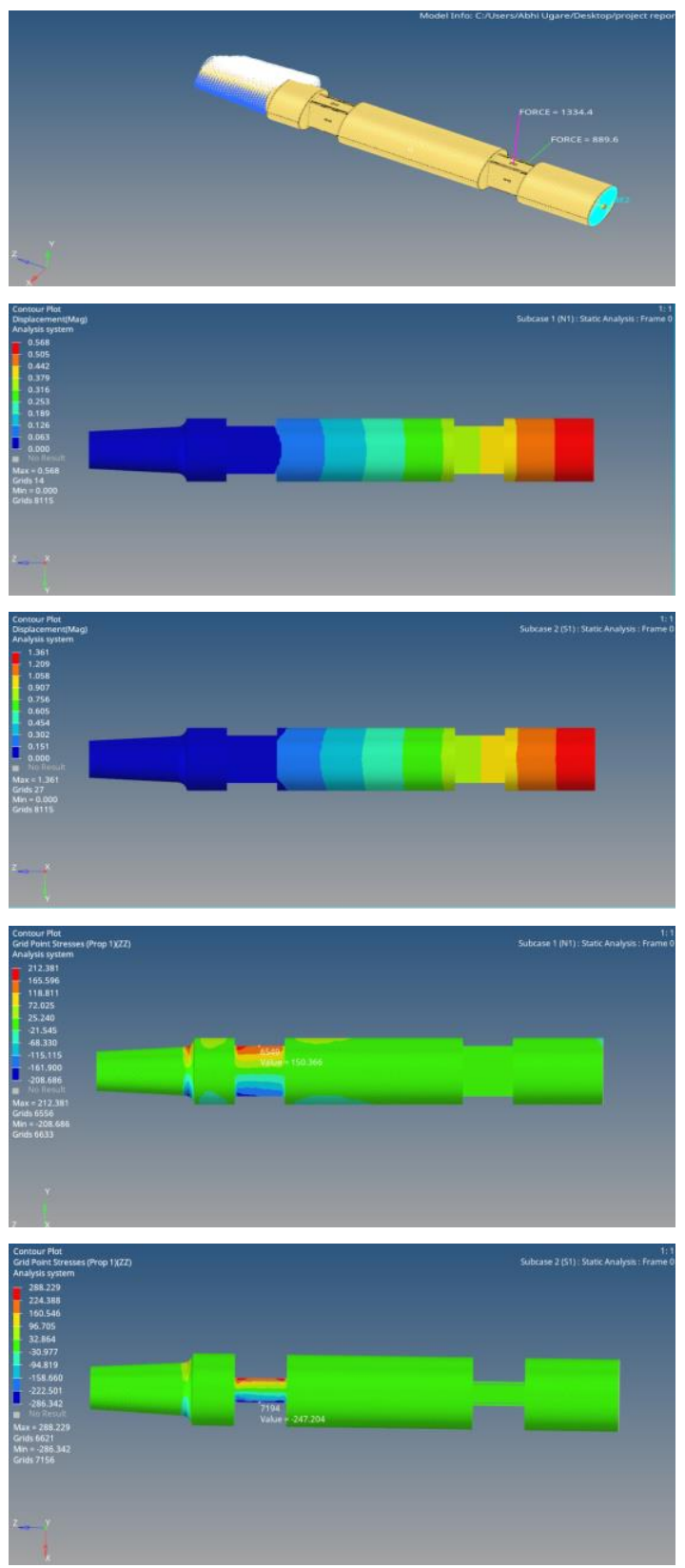

Fig.7 Steps in FEM

\section{RESULT AND DISCUSSION}

Taguchi method is used for optimizations of parameters using signal to noise ratio. Higher signal to noise ratio means closer to optimal of parameters. It can optimize the single response only and unable to optimize if the number of responses more than one. 
A. Effect of process parameters on Deformation of balance due to N1 loading only

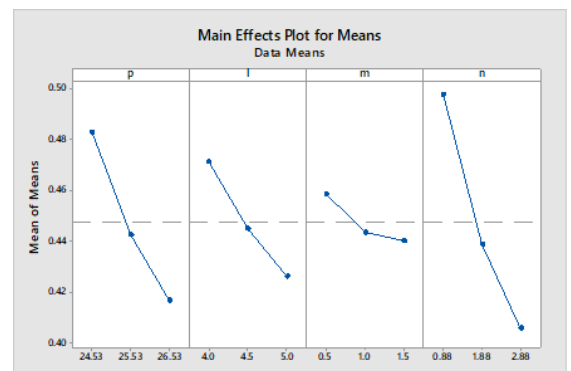

Fig 8 Mean of means for deformation due to N1 load

From the Fig. 8 it is clear that by setting parameters to level $\mathrm{p} 3,13, \mathrm{~m} 3$ and $\mathrm{n} 3$ results in minimum deformation. Parameters ' $n$ ' and 'p' are the most affecting.

\section{B. Effect of process parameters on Deformation of balance} due to S1 loading only

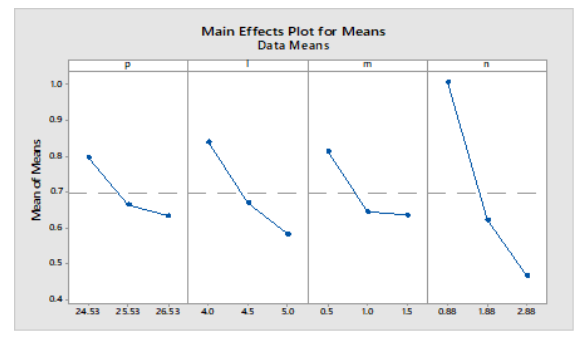

Fig. 9 Mean of means for deformation due to S1 load

From the Fig. 9 it is clear that by setting parameters to levels $\mathrm{p} 3,13, \mathrm{~m} 3$ and $\mathrm{n} 3$ results in minimum deformation and parameters ' $n$ ' is the most affecting.

C. Effect of process parameters on Strain developed at gage location for measuring N1 load due to N1 loading only.

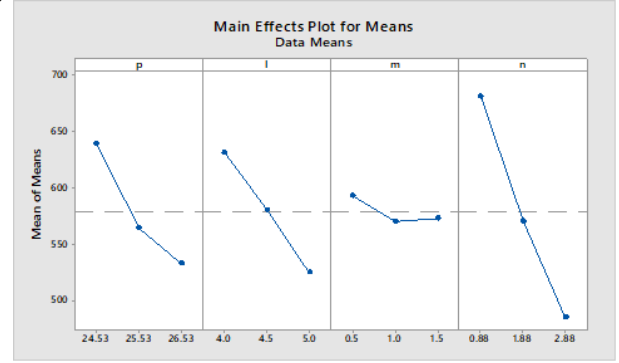

Fig 10 Mean of means for Strain developed due to N1 load

From the Fig.10 it is clear that parameter levels p1, 11, m1 and $n 1$ results in maximum strain at gage location and parameter ' $n$ ' is the most affecting.

D. Effect of process parameters on Strain developed at gage location for measuring S1 load due to S1 loading only.

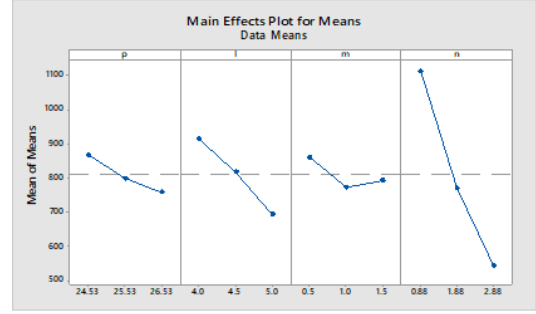

Fig.11 Mean of means for Strain developed due to S1
From the Fig.10 it is clear that parameter levels p1, 11, m1 and $\mathrm{n} 1$ results in maximum strain at gage location and parameter ' $\mathrm{n}$ ' is the most affecting

Multi response optimization using Grey relational analysis. The Taguchi method was unable to optimize multiple responses hence grey relational analysis carried out for multiple response optimization. The following steps were followed to convert $\mathrm{S} / \mathrm{N}$ ratios obtained from each response into collective form.

A. Normalization of $S / N$ ratio

The obtained $\mathrm{S} / \mathrm{N}$ ratio data from Taguchi technique were converted into normalized values using below equations 4 and 5 .

Smaller is better $=\max \left(\mathrm{x}_{\mathrm{i}}^{0}\right)-\mathrm{x}_{\mathrm{i}}^{0}(\mathrm{k}) / \max \left(\mathrm{x}_{\mathrm{i}}^{0}(\mathrm{k})\right)-\min \left(\mathrm{x}_{\mathrm{i}}^{0}(\mathrm{k})\right.$

Larger is better $=\mathrm{x}_{\mathrm{i}}{ }^{0}(\mathrm{k})-\min \left(\mathrm{x}_{\mathrm{i}}{ }^{0}(\mathrm{k})\right) / \max \left(\mathrm{x}_{\mathrm{i}}{ }^{0}(\mathrm{k})\right)-\min \left(\mathrm{x}_{\mathrm{i}}{ }^{0}(\mathrm{k})(5)\right.$ Where $x_{i}^{0}(k)$ is the value after grey relational generation, $\max \left(\mathrm{x}_{\mathrm{i}}{ }^{0}(\mathrm{k})\right)$ and $\min \left(\mathrm{x}_{\mathrm{i}}{ }^{0}(\mathrm{k})\right)$ are largest and smallest value of $\mathrm{x}_{\mathrm{i}}{ }^{0}(\mathrm{k})$.Normalized $\mathrm{S} / \mathrm{N}$ ratio is given in Table 5 .

Table 5 Normalized $\mathrm{S} / \mathrm{N}$ ratio

\begin{tabular}{|c|c|c|c|c|}
\hline SI.No & $\begin{array}{c}\text { Normalized S/N } \\
\text { ratio for } \\
\text { deformation due } \\
\text { to N1 load }\end{array}$ & $\begin{array}{c}\text { Normalized } \\
\text { S/N } \\
\text { ratio for } \\
\text { deformation } \\
\text { due to S1 load }\end{array}$ & $\begin{array}{c}\text { Normalized S/N ratio } \\
\text { for Microstrain } \\
\text { developed due N1 } \\
\text { loading }\end{array}$ & $\begin{array}{c}\text { Normalized S/N } \\
\text { ratio for } \\
\text { Microstrain } \\
\text { developed due N1 } \\
\text { loading }\end{array}$ \\
\hline $\mathbf{1}$ & 1.000 & 1.000 & 1.000 & 1.000 \\
\hline $\mathbf{2}$ & 0.505 & 0.400 & 0.548 & 0.511 \\
\hline $\mathbf{3}$ & 0.186 & 0.000 & 0.113 & 0.000 \\
\hline $\mathbf{4}$ & 0.235 & 0.238 & 0.213 & 0.239 \\
\hline $\mathbf{5}$ & 0.586 & 0.656 & 0.653 & 0.814 \\
\hline $\mathbf{6}$ & 0.253 & 0.334 & 0.218 & 0.377 \\
\hline $\mathbf{7}$ & 0.259 & 0.398 & 0.395 & 0.521 \\
\hline $\mathbf{8}$ & 0.000 & 0.186 & 0.000 & 0.155 \\
\hline $\mathbf{9}$ & 0.359 & 0.551 & 0.401 & 0.636 \\
\hline
\end{tabular}

B. Determination of Deviation sequence

The deviation sequence $\Delta_{0 \mathrm{i}}(\mathrm{k})$ is the absolute difference between the reference sequence $\mathrm{x}_{\mathrm{i}}{ }^{0}(\mathrm{k})$ and the comparability sequence $\mathrm{x}_{\mathrm{i}}{ }^{*}(\mathrm{k})$ and it is calculated from normalized value represented in Table 5 It is determined using equation 6. Values are represented in Table 6.

$\Delta_{0 \mathrm{i}}(\mathrm{k})=\mathrm{x}_{\mathrm{i}}{ }^{0}(\mathrm{k})-\mathrm{x}_{\mathrm{i}}{ }^{*}(\mathrm{k})$

Table 6 Deviation sequence

\begin{tabular}{|c|c|c|c|}
\hline $\begin{array}{c}\Delta \text { Dolk) for } \\
\text { deformation } \\
\text { due to N1 load }\end{array}$ & $\begin{array}{c}\Delta o i(k) \text { for } \\
\text { deformation } \\
\text { due to } S 1 \\
\text { load }\end{array}$ & $\begin{array}{c}\Delta o u(k) \text { for } \\
\text { Microstrain } \\
\text { developed due } \\
\text { N1 loading }\end{array}$ & $\begin{array}{c}\text { Aoi(k) for } \\
\text { Microstrain } \\
\text { developed due } \\
\text { S1 loading }\end{array}$ \\
\hline 0.000 & 0.000 & 0.000 & 0.000 \\
\hline 0.495 & 0.600 & 0.452 & 0.489 \\
\hline 0.814 & 1.000 & 0.887 & 1.000 \\
\hline 0.765 & 0.762 & 0.787 & 0.761 \\
\hline 0.414 & 0.344 & 0.347 & 0.186 \\
\hline 0.747 & 0.666 & 0.782 & 0.623 \\
\hline 0.741 & 0.602 & 0.605 & 0.479 \\
\hline 1.000 & 0.814 & 1.000 & 0.845 \\
\hline 0.641 & 0.449 & 0.599 & 0.364 \\
\hline
\end{tabular}

\section{Calculation of Grey relational Coefficient}

GRC are calculated to express the relationship between the ideal and actual normalized $\mathrm{S} / \mathrm{N}$ ratio. The grey relational coefficient can be expressed by equation 7 and values are represented in Table 7.

$\Upsilon_{0 \mathrm{i}}(\mathrm{k})=\left(\Delta_{\min }+\zeta \Delta_{\max }\right) /\left(\Delta_{0 \mathrm{i}}(\mathrm{k})+\zeta \Delta_{\max }\right)$

Where , $\Delta_{0 \mathrm{i}}$ is the deviation sequence of the reference sequence and the comparability sequence and $\Delta_{0 \mathrm{i}}=\mathrm{x}_{\mathrm{i}}{ }^{0}(\mathrm{k})$ $\mathrm{x}_{\mathrm{i}}{ }^{*}(\mathrm{k})$ where $\mathrm{x}^{0} \mathrm{k}$ implies the reference sequence and $\mathrm{x}_{\mathrm{i}} \mathrm{k}$ 
termed as comparability sequence. $\Delta_{\min }$ and $\Delta_{\max }$ are the minimum and maximum values of the absolute differences $\left(\Delta_{0 \mathrm{i}}\right)$ of all comparing sequences. $\zeta$ is distinguishing or identification coefficient and the range is between 0 to 1 . Usually, the value of $\zeta$ is taken as 0.5 .

Table 7 Grey relational grade and Rank

\begin{tabular}{|c|c|c|c|c|c|c|}
\hline Sl.No & $\begin{array}{l}\text { GRC for } \\
\text { deformation } \\
\text { due to N1 } \\
\text { load }\end{array}$ & $\begin{array}{c}\text { GRC for } \\
\text { deformation } \\
\text { due to N1 } \\
\text { load }\end{array}$ & $\begin{array}{c}\text { GRC for } \\
\text { Microstrain } \\
\text { developed } \\
\text { due N1 } \\
\text { loading }\end{array}$ & $\begin{array}{c}\text { GRC for } \\
\text { Microstrain } \\
\text { developed } \\
\text { due N1 } \\
\text { loading }\end{array}$ & GRG & RANK \\
\hline $\mathbf{1}$ & 1 & 1 & 1 & 1 & 1 & 1 \\
\hline $\mathbf{2}$ & 0.503 & 0.455 & 0.525 & 0.506 & 0.49725 & 4 \\
\hline $\mathbf{3}$ & 0.381 & 0.333 & 0.36 & 0.333 & 0.35175 & 9 \\
\hline $\mathbf{4}$ & 0.395 & 0.396 & 0.388 & 0.396 & 0.39375 & 7 \\
\hline $\mathbf{5}$ & 0.547 & 0.593 & 0.59 & 0.729 & 0.61475 & 2 \\
\hline $\mathbf{6}$ & 0.401 & 0.429 & 0.39 & 0.445 & 0.41625 & 6 \\
\hline $\mathbf{7}$ & 0.403 & 0.454 & 0.453 & 0.511 & 0.45525 & 5 \\
\hline $\mathbf{8}$ & 0.333 & 0.381 & 0.333 & 0.372 & 0.35475 & 8 \\
\hline $\mathbf{9}$ & 0.438 & 0.527 & 0.455 & 0.579 & 0.49975 & 3 \\
\hline
\end{tabular}

\section{Determination of weighted grey relational grade}

Grey relational grade was calculated by computing average of grey relational coefficients as given in equation number 8 . The overall output response depends on calculated Grey relational grade rank. The values of GRG and Ranks represented in Table 7.

$\Upsilon\left(\mathrm{x}_{0}, \mathrm{x}_{\mathrm{i}}\right)=\frac{1}{m} \sum_{i=1}^{m}(\mathrm{x} 0(\mathrm{k}), \mathrm{xi}(\mathrm{k}))$

Where $\Upsilon\left(\mathrm{x}_{0}, \mathrm{x}_{\mathrm{i}}\right)$ the grey relational grade for the $\mathrm{i}^{\text {th }}$ experiment and $\mathrm{m}$ is the number of performance characteristics.

It is evidently observed from Table 7 that grey relational grade that analysis No.1 has the highest grey relational grade of value 1 , therefore the first number analysis gives the best multiple performance characteristics among the nine analysis carried. Ultimately, larger the grey relational grade, better the corresponding multi-objective characteristics.

\section{E. Analysis of variance}

The obtained GRG is considered as a single response for designed experiments and ANOVA was carried out for finding most significant geometrical parameters which affect the multi objective response. In the present research work ANOVA is carried out on Minitab 2018. ANOVA is given in Table 8 ANOVA calculations are based on F-ratio.

Table 8 Analysis of Variance

\begin{tabular}{|c|c|c|c|c|c|c|c|}
\hline Source & DF & Seq SS & Contribution & Adj SS & Adj MS & F-Value & P-Value \\
\hline$p$ & 2 & 0.05378 & $16.51 \%$ & 0.05378 & 0.02689 & * & * \\
\hline I & 2 & 0.05817 & $17.86 \%$ & 0.05817 & 0.02909 & * & * \\
\hline $\mathrm{m}$ & 2 & 0.02973 & $9.12 \%$ & 0.02973 & 0.01486 & * & \\
\hline$n$ & 2 & 0.18410 & $56.51 \%$ & 0.18410 & 0.09205 & * & * \\
\hline Error & 0 & * & * & * & * & & \\
\hline Total & 8 & 0.32578 & $100.00 \%$ & & & & \\
\hline
\end{tabular}

ANOVA table shows the percentage contribution of each parameter. It is clear from ANOVA table that parameter only ' $\mathrm{n}$ ' is significant for multi objective response with contribution of $56.51 \%$ whereas remaining parameters $1, \mathrm{p}, \mathrm{m}$ contributing $17.86 \%, 16.51 \%$ and $9.12 \%$ respectively are less significant. Using Taguchi method, response table has been generated to separate out the effect of each level of process parameters on grey relational grade as represented in Table 9.
Table 9 Response table for GRG

\begin{tabular}{lrrrr}
\multicolumn{5}{c}{$\begin{array}{l}\text { Response Table for Means } \\
\text { Level }\end{array}$} \\
$\mathrm{p}$ & $\mathrm{I}$ & $\mathrm{m}$ & $\mathrm{n}$ \\
\hline 1 & 0.6163 & 0.6163 & 0.5903 & 0.7048 \\
2 & 0.4749 & 0.4889 & 0.4636 & 0.4562 \\
3 & 0.4366 & 0.4226 & 0.4739 & 0.3667 \\
Delta & 0.1797 & 0.1937 & 0.1267 & 0.3381 \\
Rank & 3 & 2 & 4 & 1
\end{tabular}

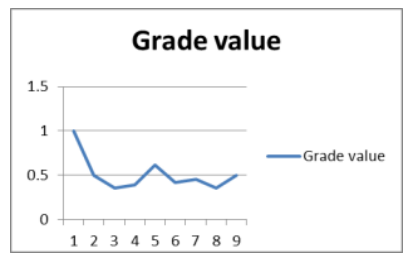

Fig. 12 Graph shows ranking of experiment no.with respect to grade value

Based on the ranking order obtained from Table 7 and Fig 12 experiment No.1 is considered best response value. Basically, larger the grey relational grade, better the corresponding characteristics. From the response table for grey relational grade, the best combination of the process parameters is set with $\mathrm{p} 1,11, \mathrm{~m} 1, \mathrm{n} 1$.

\section{F. Results comparison with cross beam flexures}

The cross beam flexure balance with diameter of $=31.75 \mathrm{~mm}$ and length of $261.20 \mathrm{~mm}$ used as reference for studying performance of newly proposed flexure structure. The cross beam flexure shown in Fig. 13.

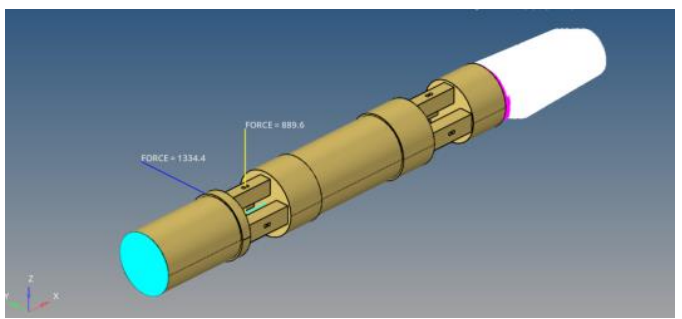

Fig. 13 Cross beam flexure

The newly proposed three parallel rectangular beam flexures compared with cross beam flexure of same diameter and material for Sensitivity and Rigidity due to Normal force and side force. The deformation due $\mathrm{N} 1$ and $\mathrm{S} 1$ load are more than that of cross beam with increase of $4.72 \%$ and $223.36 \%$ which is not desirable, where as Sensitivity(Bridge output) for N1 and $\mathrm{S} 1$ load increased by $5.63 \%$ and $79.18 \%$.

\section{CONCLUSIONS}

The aim of this work was to find optimum shape of three parallel rectangular beam flexure for improved Rigidity and Sensitivity .Design of experiment techniques have been utilized for investigation and optimization of selected parameters, in order to get better response. The conclusion based on multi objective optimization using Taguchi based Grey relational analysis are summarized as follows:

The maximum deformation due to $\mathrm{N} 1$ loading is $0.598 \mathrm{~mm}$ and S1 loading is $1.48 \mathrm{~mm}$ which are greater than that of cross beam flexure(used as reference) by $4.72 \%$ and $223.36 \%$ respectively which is not desirable. These large deformations 
for given loading case cause divergence as stability issue and grounding during load path transfer, which results in erroneous results. The Wheatstone Bridge output for $\mathrm{N} 1$ loading is $1.726 \mathrm{mV} / \mathrm{V}$ and for $\mathrm{S} 1$ loading is $2.772 \mathrm{mV} / \mathrm{V}$ which are greater than that of cross beam flexure (used as reference) by $5.63 \%$ and $79.18 \%$ respectively. Using GRA the optimum parameters levels obtained and Analysis of Variance resulted that parameter 'n' has the highest contribution of $56.51 \%$.Parameter ' $n$ ' has major influence on Sensitivity and Rigidity.

\section{REFERENCES}

[1] N.M. Nouri,Karim Mostafapour,MaryamKamran, Robab Bohadori, "Design methodology of a six-component balance for measuring forces and moments in water tunnel tests" Measurement 58(2014) 544-555.

[2] Abdelwahid Boutemedjet a , Marija Samardžić b, Dušan Ćurčić b , Zoran Rajić b , Goran Ocokoljić," Wind tunnel measurement of small values of rolling moment using six- component strain gauge balance",Measurement 116 (2018) 438-450.
[3] Swapna L. Bharath Katta , B. S. Suresh, Shape Optimization of a Drag Force Element of a Force Transducer for Wind Tunnel Measurements, Journal of Mechanical Engineering and Automation 5(3B),2015, 33-38.

[4] Iranna Hanapur , Dr. S. G. Gopalakrishna, Design Optimization of 25mm Diameter Strain Gauge Balance for Wind Tunnel Application, IJIRST -International Journal for Innovative Research in Science \& Technology| Volume 3 | Issue 02 | July 2016,235-247.

[5] Rakesh Kolhapure, Vasudev Shinde, Vijay Kamble, Geometrical optimization of strain gauge force transducer using GRA method, Measurement 101 (2017) 111-117. 